DOI: https://doi.org/10.24867/03BE06Buzadzija

\title{
PRIKLJUČENJE BIOGASNOG POSTROJENJA NA DISTRIBUTIVNI SISTEM SREDNJEG NAPONSKOG NIVOA
}

\section{CONNECTION OF THE BIOGAS PLANT TO THE MEDIUM VOLTAGE DISTRIBUTION SYSTEM}

\author{
Bojan Buzadžija, Zoltan Čorba, Fakultet tehničkih nauka, Novi Sad
}

\section{Oblast - ELEKTROTEHNIKA I RAČUNARSTVO}

Kratak sadržaj- $U$ ovom radu je teorijski, praktično $i$ eksperimentalno predstavljeno biogasno postrojenje priključenona distributivni sistem srednjeg naponskog nivoa. Na početku rada je dat teorijski uvod o obnovljivim izvorima električne energije (biogas) i Pravilima o radu distributivnog sistema. Nakon ovoga je analiziran primer priključenja biogasne elektrane na distributivni sistem električne energije $i$ obrađeni su rezultati merenja parametara električne energije da bi se utvrdilo da li elektrana zadovoljava uslove za priključenje na distributivni sistem električne energije (DSEE).

Ključne reči: Pravila o radu DS, Parametri električne energije, Srednjenaponski nivo, Biogasna elektrana

Abstract -In this paper, the biological plant connected to the distribution system of the medium voltage level is theoretically, practically and experimentally presented.At the beginning of the paper a theoretical introduction on renewable electricity sources was given (biogas) and the operating rules of the distribution system. After this, an example of the connection of the biogas plant to the distribution system of elektricity is analyzed and the results of the measurement of the parameters of electrical energy were processed to determine whether the plant meets the requirements for connection to the distribution system of electricity (DSE).

Key words: Rules on the operation of the distribution system, Parameters of electrical energy, Medium voltage level, Biogas power plant

\section{UVOD}

Postoji više načina da se iz obnovljivih izvora dobije električna energija. To su energija vodotokova, vetra, sunčeva energija, biomasa, geotermalna energija i druge. Od svih navedenih, u ovom radu je akcenat na procesu dobijanja električne energije iz energije biogasa [1].

Biogasna elektrana za priključenje na distributivni sistem srednjeg naponskog nivoa, mora da zadovolji uslove iz Pravilnika o radu distributivnog sistema i Tehničke preporuke Elektroprivrede Srbije. Gas koji se oslobađa iz fermentora, pokreće turbine gasnog generatora koji proizvodi električnu energiju. Proizvedena energija se preko niskonaponskog $(\mathrm{NN})$ i visokonaponskog (VN) postrojenja u transformatorskoj stanici (TS) elektrane

\section{NAPOMENA:}

Ovaj rad proistekao je iz master rada čiji mentor je bio dr Zoltan Čorba, docent. prenosnog odnosa transformatora, prenosi u mrežu. Mesto priključenja elektrane na DSEE je opremljen $20 \mathrm{kV}$ rasklopnim postrojenjem, daljinskom stanicom i obračunskim merenjem. Naveden je konkretan primer jedne biogasne elektrane, izvršeno je merenje parametara električne energije u niskonaponskom bloku koji se nalazi u TS elektrane i iz dobijenih razultata su izvučeni zaključci, da li dobijene vrednosti odgovaraju parametrima koji su navedeni kao uslov za priključenje na DSEE.

\section{PRAVILA I PREPORUKE PRIKLJUČENJA MALE ELEKTRANE NA SREDNJI NAPONSKI NIVO}

Pravila i preporuke priključenja male elektrane na DS propisuje nadležni operator DS. Operator DS (ODS) propisuje uslove za priključenje kako bi obezbedio siguran paralelan rad DS i male elektrane (ME).

$\mathrm{Za}$ priključenje i bezbedan paralelan $\mathrm{rad} \mathrm{ME}$ sa DS, elektrana mora da zadovolji kriterijum maksimalno dozvoljene snage generatora u elektrani, kriterijum dozvoljenih vrednosti napona u stacionarnom režimu, kriterijum dozvoljenog strujnog opterećenja elemenata distributivne mreže, kriterijum snage kratkog spoja (KS), kriterijum flikera i kriterijum dozvoljenih struja viših harmonika i interharmonika.

Kriterijumom maksimalno dozvoljene snage generatora u elektrani sa energetskim pretvaračima ili asinhronim generatorima proverava se da pri uključenju generatora promena napona na mestu priključenja na DS ne prekorači vrednost od $2 \%$ na SN, odnosno $3 \%$ na NN. Maksimalno dozvoljena prividna snaga generatora $\mathrm{u}$ elektrani $\left(S_{n g m}\right)$ u [MVA] izračunava se prema sledećim formulama: za priključenje na $\mathrm{SN}$,

$$
S_{n g m}=\frac{S_{K S}}{50 * k}
$$

za priključenje na $\mathrm{NN}$,

$$
S_{n g m}=\frac{S_{K S}}{3,33 * k}
$$

gde je $S_{K S}$ snaga trofaznog kratkog spoja, u [MVA].

Kriterijumom dozvoljenih vrednosti napona u stacionarnom režimu proverava se tako da u okviru normalnog pogona DS, vrednost napona u bilo kojoj tački DS ostane u dopuštenim granicama.

Kriterijumom dozvoljenog strujnog opterećenja elemenata distributivne mreže se proverava, da za vreme rada elektrane, struje u elementima DS ne pređu propisane vrednosti. 
Kriterijumom snage KS se proverava ukupna vrednost struje trofaznog KS (snaga) na mestu priključenja elektrane u pogonu. Vrednost struje ne sme preći maksimalne dozvoljene vrednosti struja KS na koje je dimenzionisana oprema u DS.

Kad je kriterijum flikera u pitanju elektrana sa n generatora ukupne snage $S_{E}$ može da se priključi na DS ako je ispunjen uslov:

$$
A_{I t}=\left(c_{f E} * \frac{S_{E}}{S_{k s}}\right)^{3}=\left(\frac{c_{f g}}{\sqrt{n}} * \frac{S_{E}}{S_{k s}}\right)^{3} \leq 0,1
$$

gde je: $A_{I t}$ dugotrajni faktor smetnji elektrane, $c_{f E}$ koeficijent flikera elektrane $\mathrm{i} c_{f g}$ koeficijent flikera generatora.Koeficijent flikera označava osobinu elektrane da proizvodi flikere.

Kriterijum dozvoljenih struja viših harmonikase proverava pomoću izraza:

$$
I_{v h g} \leq I_{v h d o z}=I_{v h s v \mu} * S_{K S}
$$

gde je: $I_{v h g}$ stvarna i $I_{v h d o z}$ dozvoljena vrednost struje višeg harmonika u [A], a $I_{v h s ~} \mu$ je dozvoljenavrednost struje višeg harmonikasvedena na jediničnu snagu KS na mestu priključenja na DS u [A/MVA].

Dozvoljene vrednosti struja viših harmonika svedenih na snagu KS su date u tabeli 1.Ugradnjom odgovarajućih zaštitnih i drugih tehničkih uređaja u elektrani, treba obezbediti da uključenje elektrane na DS bude izvršeno samo ako je na svim faznim provodnicima prisutan napon mreže sa strane DS.

Elektrana se povezuje na DS samo preko jednog priključka izuzimajući priključak opšte potrošnje elektrane i ostale potrošnje na lokaciji elektrane.

Kada je u pitanju zaštita generatora i elektrane postoje sistemska zaštita, zaštita od ostrvskog rada i zaštita voda elektrane.

Faktor snage elektrane u odnosu na DS treba da je veći od 0,95 u kapacitivnom i induktivnom režimu rada.

Elektrana mora biti opremljena odgovarajućom opremom, softverom i komunikacionim servisom radi dostavljanja neophodnih podataka, mora da se obezbedi oprema koja će omogućiti prenos informacija do nadležnog centra upravljanja ODS.

\section{PRIMER PRIKLJUČENJA BIOGASNOG POSTROJENJA NA DISTRIBUTIVNI SISTEM SREDNJEG NAPONSKOG NIVOA}

Primer priključenja biogasnog postrojenja na DS je prikazan na elektrani koja je izgrađena u Čurugu, koristeći podatke, informacije $\mathrm{i}$ iskustva na izgradnji tog postrojenja. Na slici 1. prikazana je šema generatora elektrane i ZTS ,Velvet farm ME“. Prikazani su $20 \mathrm{kV}$ vodovi za priključenje elektrane na DSEE, novo prefabrikovano $20 \mathrm{kV}$ razvodno postrojenje u SF6 tehnici proizvođača „SIEMENS“, NN razvod za napajanje sistema daljinskog upravljanja i nadzora (SDUN).Izgled $20 \mathrm{kV}$ razvodnog postrojenja je dat na slici 2. U okviru postrojenja se nalaze: V-1 vodna ćelija prema ČRS-u br. 35 "Izvod Čurug", V-2 spojna ćelija, M-1 napajanje RTU daljinske stanice, M-2 obračunsko merenje OMM3, V-3 TS "Velvet farm ME" Generator 1, V-4 TS "Velvet farm ME" Generator 2, M-3 obračunsko merenje OMM2, V-5
MBTS "Budućnost", V-6 spojna ćelija, M-4 obračunsko merenje OMM1, T-1 trafo polje 1, T-2 trafo polje $2 \mathrm{i}$ V-7 sopstvena potrošnja TS "Velvet farm ME”.

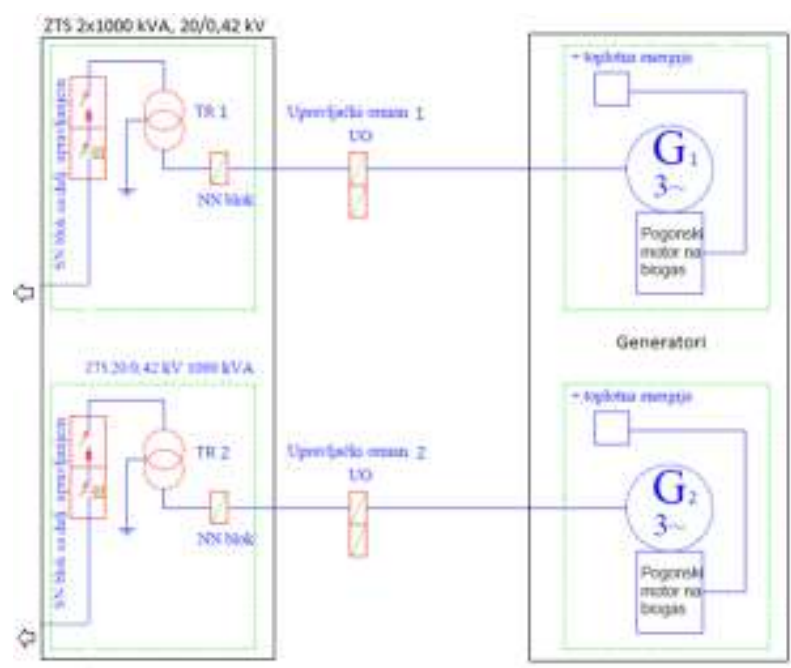

Slika 1. Šematski prikaz generatora biogasne elektrane $i$ ZTS "Velvet farm ME"

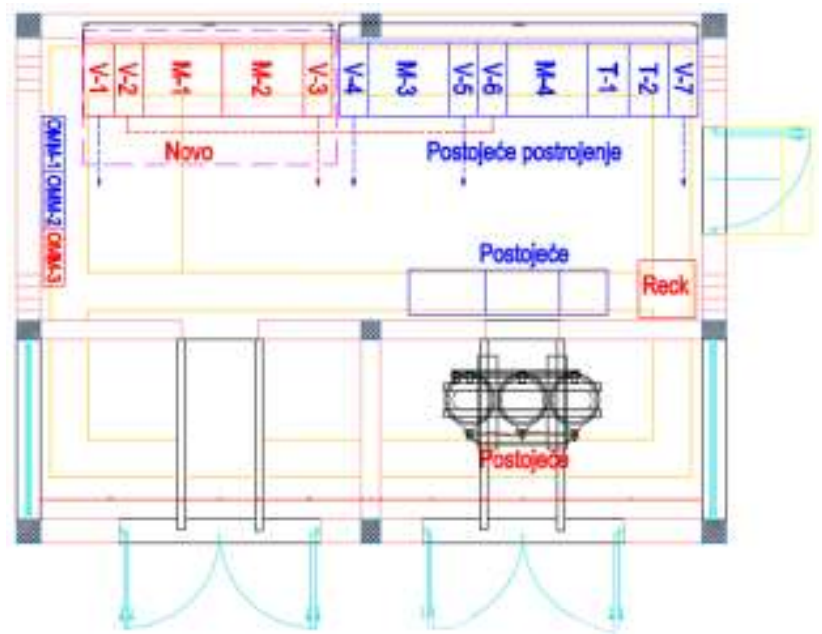

Slika 2.TS “Velvet farm”20/0,4 kV/kV (I i II faza izgradnje)

Nazivni naponi $U_{n}$ distributivne mreže, na koju se priključuje $\mathrm{ME}$ je $U_{n}=20 \mathrm{kV}$, dok je vrednosti maksimalne dozvoljene struje (snage) trofaznog KS i struje zemljospoja od 14,5 kA (500 MVA).Stvarna struja trofaznog KS sa strane DSEE na mestu priključenja elektrane na DSEE, u subtranzijentnom periodu je $I_{k s}=1,316 k A$, odnos $\mathrm{R} / \mathrm{X}=0,803$. Elektroenergetska oprema u DSEE na $20 \mathrm{kV}$ naponu je dimenzionisana na dozvoljenu strujutrofaznog kratkog spoja 14,5 kA.

Distributivna mreža $20 \mathrm{kV}$ ima radijalno napajanje iz prenosnog sistema i uvođenjem $\mathrm{ME}$ ona više nije radijalno napajana. Uzemljenje neutralne tačke distributivne mreže $20 \mathrm{kV}$, izvode se tako što je neutralna tačka mreže $20 \mathrm{kV}$ izolovana ili uzemljena preko niskoomske impedance.

Sinhroni generator pokreće se preko elastičnog gasnog motora. Generator se izrađuje kao samoregulišući sinhroni generator i sa potrebnom opremom i pomoćnim komponentama. Podaci o generatoru: kogeneraciono postrojenje J 312 GS-D25 Stamford CG634, pogonska snaga $788 \mathrm{kVA}$ odnosno $1134 \mathrm{~A} \operatorname{pri} \cos \varphi=0,8$, 
nominalan aktivan učinak $635 \mathrm{~kW}$, napon $400 \mathrm{~V}$, frekvencija $50 \mathrm{~Hz}$, broj obrtaja $1500 \%$ min, vrsta zaštite IP 23 i klasa izolacije $\mathrm{H}$.

Rasklopna oprema u ćelijama novog $20 \mathrm{kV}$ postrojenja u OMP je u skladu sa koncepcijom ODS-a, rasklopni aparati su daljinski upravljani.

U objektu mesta priključenja (OMP) je ugrađena daljinska stanica i u neposrednoj blizini je postavljen novi antenski stub, na koji je montirana antena radi komunikacije sa nadređenim dispečerskim centrom, a koja je povezana sa daljinskom stanicom.Komunikacija sa daljiskom stanicom se realizuje se komunikacionim IEC 61850 putem fiberoptičkog kabla, a može se realizovati i po principu Scada-Scada.

U sklopu priključka je ugrađen merni uređaj za obačunsko merenje primopredaje električne energije između ME i DSEE, koji se smešta $u$ orman mernog mesta tipa MOMM-PI/2 i povezuje se sa mernim transformatorima $u$ mernoj ćeliji. Navedeni orman mernog mesta se montira na zid unutar OMP [3, 4].

\section{ANALIZA MERENJA PARAMETARA ELEKTRI- ČNE ENERGIJE BIOGASNOG POSTROJENJA}

Sa uređajem za merenje kvaliteta električne energije izvršeno je merenje u bloku niskog napona (BNN) biogasne elektrane.

Po priključenju uređaja za merenje memorisane su trenutne vrednosti napona i struje, sva tri napona istovremeno, sve tri struje istovremeno i struje i naponi po fazama.

Na slici 3. prikazano je priključenje mernog uređaja u NN bloku TS male elktrane (ME).

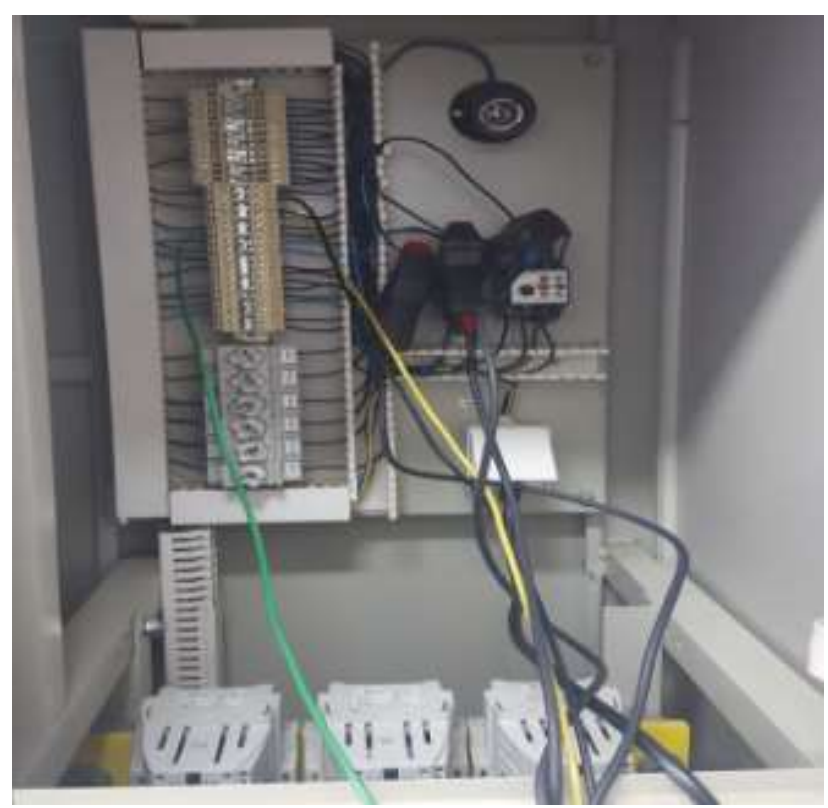

Slika 3. Priključenje uređaja za merenje

Zabeleženi su sledeći parametri električne energije: frekvencija, međufazni napon sve tri faze, struja sve tri faze, ukupno harmonijsko izobličenje napona THDU, ukupno harmonijsko izobličenje struje THDI, aktivna snaga $\left(W_{\text {total }}\right)$, faktor snage $\left(P F, P F_{\text {mean }}\right)$ i harmonike $R M S_{2}$ (od 2-25 harmonika).

$\mathrm{Na}$ slici 4. prikazan je međufazni napon, dok je na slici 5. prikazana aktivna snaga.

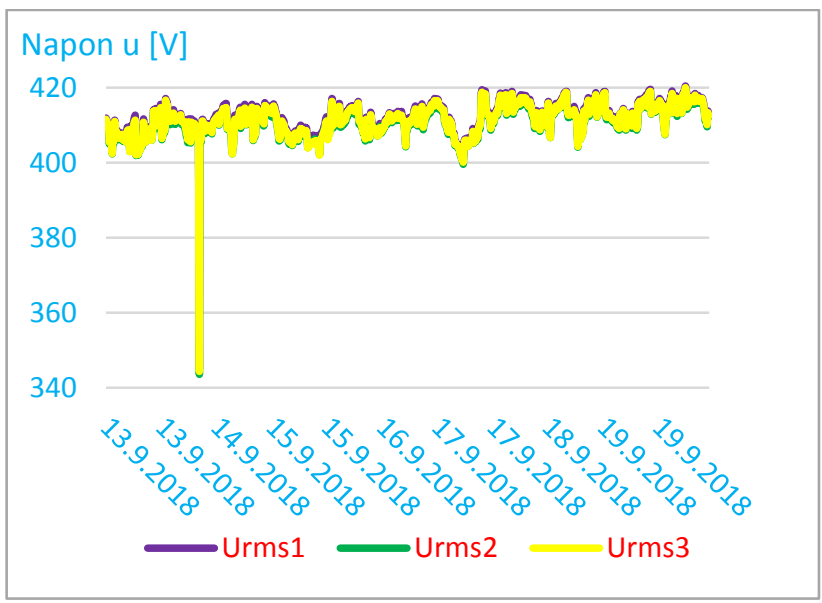

Slika 4. Međufazni napon

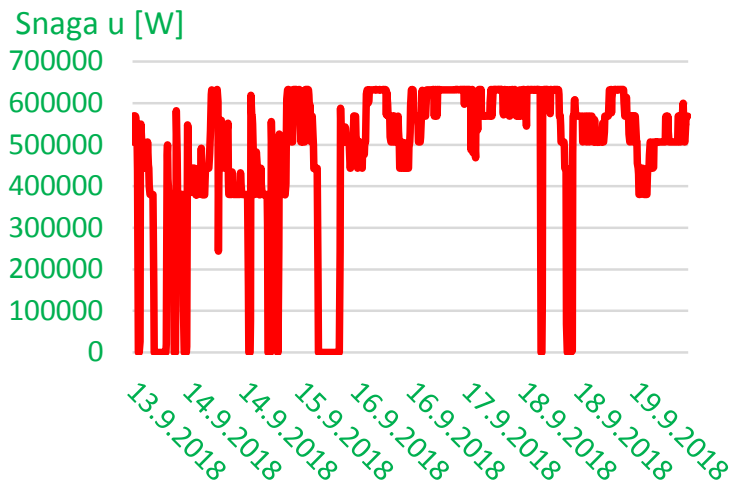

Slika 5. Aktivna snaga

Na slici 6, 7 i 8 su redom prikazane THD napona, THD struje i faktor snage.

THDU u [\%]

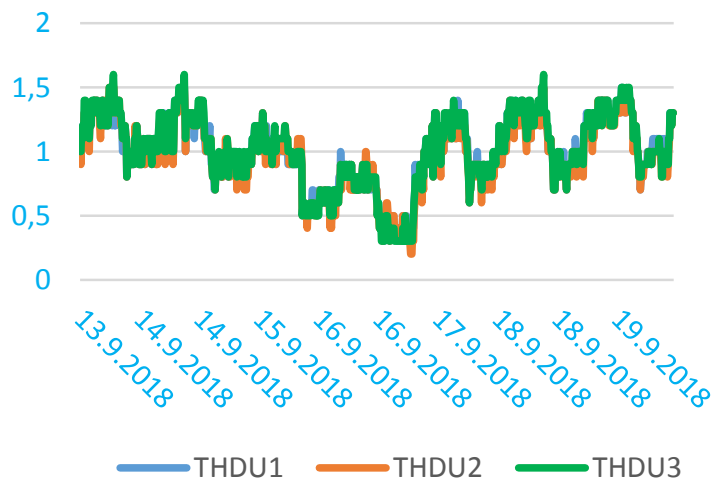

Slika 6. Totalna harmonijska distorzija napona

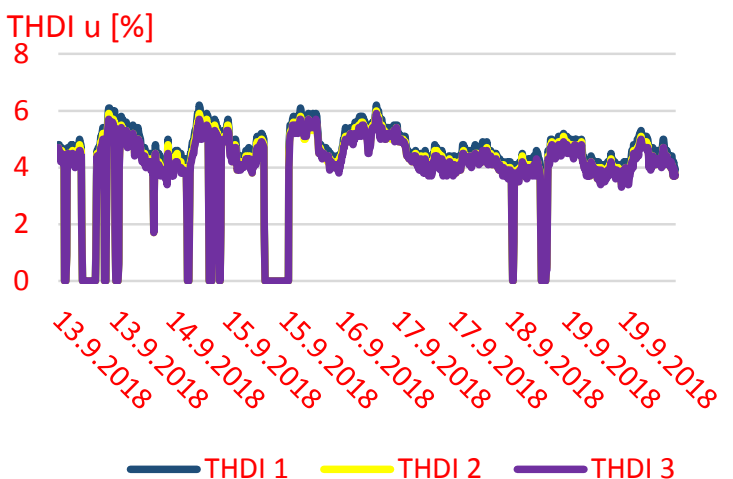

Slika 7. Totalna harmonijska distorzija struje 


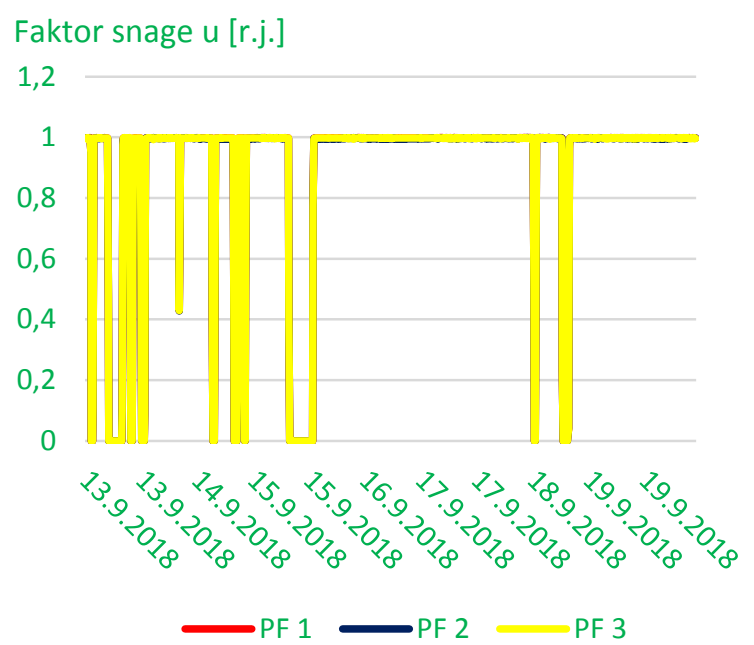

Slika 8. Faktor snage za sve tri faze

Prikazani grafici su dobijeni kao rezultat merenja parametara električne energije u ME. Maksimalna vrednost napona na sve tri faze iznosi $420,5 \mathrm{~V}$, a minimalna 343,6 V. Minimalna vrednost napona je zabeležena 14.09.2018. u 08:50h, što nam govori da je u tom trenutku došlo do propada napona ili kratkotrajnog prekida pošto je usrednjavanje na 10 minuta. Izuzimajući taj propad napona, minimalna vrednost napona iznosi $399,6 \mathrm{~V}$, što je prihvaljivih $+/-10 \% U_{n}$. Maksimalna vrednost aktivne snage iznosi $633,314 \mathrm{~kW}$. Maksimalna vrednost THDU iznosi $1,6 \%$, dok je minimalna vrednost $0,2 \%$. Vrednosti THDU su manje od $8 \%$, što ispunjava propisane standarde SRPS EN 50160. Maksimalna vrednost totalne harmonijske distorzije struje iznosi $6,2 \%$.

\subsection{Provera kriterijuma harmonijskih izobličenja}

Upoređivanjem rezultata merenja stvarne vrednosti struje generatora $I_{v h g}$ sa dozvoljenom vrednošću struje na mestu priključenja $I_{v h d o z}$, koja se dobija proizvodom dozvoljenih vrednosti struja za naznačeni naponski nivo $U_{n}=0,4 \mathrm{kV}$ i snage $\mathrm{KS}$ generatora $S_{K S}=\sqrt{ } 3 * U_{n} * I_{k s}$ za $I_{k s}=1,316 \mathrm{kA}$.

Iz dobijenih vrednosti prikazanih u tabeli 1. dolazimo do zaključka da izmerene vrednosti struja viših harmonika su manje i/ili jednake sa maksimalnim dozvoljenim strujama viših harmonika:

$$
I_{v h g} \leq I_{v h d o z}
$$

Znak + $\mathrm{u}$ tabela 1. predstavlja pozitivan rezultat, $\mathrm{tj}$. ispunjenje uslova kriterijuma dozvoljenih vrednosti harmonika struje. Kako 5. harmonik ne ispunjava uslov, neophodan je filter za 5 . harmonik ili da se izvrši ponovno merenje parametara električne energije radi ponovne provere ispunjenja kriterijuma.

Tabela 1. Dozvoljene $i$ stvarne vrednosti struja viših harmonika

\begin{tabular}{|c|c|c|c|c|}
\hline Harmonik & $\begin{array}{c}I_{v h s ~} \mu \mu \\
{[\mathrm{A}]}\end{array}$ & $\begin{array}{c}I_{v h d o z} \text { max } \\
{[\mathrm{A}]}\end{array}$ & $\begin{array}{c}I_{v h g} \\
{[\mathrm{~A}]}\end{array}$ & Komentar \\
\hline 2 & 0,029 & 1,321 & 0,005 & + \\
\hline 3 & $/$ & $/$ & 0,318 & + \\
\hline 4 & 0,009 & 0,410 & 0,000 & + \\
\hline $\mathbf{5}$ & $\mathbf{0 , 0 2 9}$ & $\mathbf{1 , 3 2 1}$ & $\mathbf{1 , 7 4 0}$ & - \\
\hline 6 & 0,012 & 0,546 & 0,000 & + \\
\hline 7 & 0,041 & 1,867 & 0,249 & + \\
\hline
\end{tabular}

\begin{tabular}{|c|c|c|c|c|}
\hline 8 & 0,004 & 0,182 & 0,000 & + \\
\hline 9 & $/$ & $/$ & 0,030 & + \\
\hline 10 & 0,007 & 0,319 & 0,000 & + \\
\hline 11 & 0,026 & 1,834 & 0,094 & + \\
\hline 12 & 0,005 & 0,228 & 0,000 & + \\
\hline 13 & 0,019 & 0,865 & 0,039 & + \\
\hline 14 & 0,003 & 0,137 & 0,000 & + \\
\hline 15 & $/$ & $/$ & 0,000 & $/$ \\
\hline 16 & 0,003 & 0,137 & 0,000 & + \\
\hline 17 & 0,011 & 0,501 & 0,025 & + \\
\hline 18 & 0,002 & 0,091 & 0,000 & + \\
\hline 19 & 0,009 & 0,410 & 0,000 & + \\
\hline 20 & $/$ & $/$ & 0,000 & $/$ \\
\hline 21 & $/$ & $/$ & 0,000 & $/$ \\
\hline 22 & $/$ & $/$ & 0,000 & $/$ \\
\hline 23 & 0,006 & 0,273 & 0,000 & + \\
\hline 24 & $/$ & $/$ & 0,000 & $/$ \\
\hline 25 & 0,005 & 0,228 & 0,000 & + \\
\hline
\end{tabular}

\section{ZAKLJUČAK}

Izgradnjom $\mathrm{ME}$ se poboljšava pouzdanost $\mathrm{i}$ kvalitet EES.Za pravilno funkcionisanje novoizgrađenih ME i TS za priključenje na DSEE, obavezno je poštovanje svih obrađenih uslova iz pravila o radu DS i propisa. Izgrađene TS i oprema su u skladu sa propisanim standardima, ispunjavaju sve uslove zaštite, kvaliteta, sigurnosti i puzdanosti. Analizom parametara i poređenjem sa pravilima, došlo se do zaključka da ME ispunjava uslove za bezbedan rad i za bezbedno priključenje na DSEE srednjeg naponskog nivoa.

\section{LITERATURA}

[1] Oficijalni sajt kompanije "Global Seed" DOO, Čurug (poslovni sistem)

http://www.globalseed.info/obnovljivi-izvorienergije.php

[2] Pravila o radu distributivnog sistema - "EPS Distribucija" DOO Beograd

[3] Uslovi za projektovanje i priključenje, "EPS Distribucija" DOO Beograd, Ogranak "Elektrodistribucija Novi Sad", Pogon Žabalj

[4] Idejni projekat IDP G-520 od Februara 2018. Izgradnja II faze, rekonstrukcija

\section{Kratka biografija:}

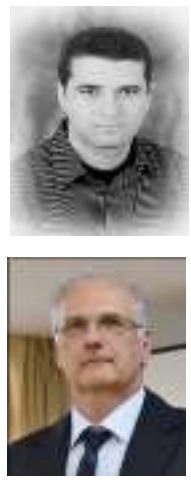

Bojan Buzadžijaje rođen u Novom Sadu 1990. godine. Diplomski rad na Fakultetu Tehničkih Nauka u Novom Sadu iz oblasti Elektrotehnika i Računarstvo - energetska elektronika i električne mašine odbranio je 2016. godine.

Zoltan Čorba je docent na Fakultetu tehničkih nauka u Novom Sadu, na katedri za Energetsku elektroniku i pretvarače. Oblast interesovanja su obnovljivi izvori i kvalitet električne energije. 